\title{
LA INTERVENCIÓN ESTATAL EN LA ECONOMÍA: ELEMENTOS DE ANÁLISIS PARA EL CASO COLOMBIANO
}

Fray Luis Antonio Alfonso Vargas, O.P.

Maestría en Derecho Público (C), Universidad Santo Tomás- Seccional Bucaramanga (Col); Abogado Universidad Católica de Colombia, (Col); Estudios de Filosofía y Teología en el Studium Generale de la Provincia San Luis Bertrán; Abogado Universidad Católica de Colombia (Col); Docente Facultad de Derecho, Universidad Santo Tomás Seccional Tunja. E-mail: lusialfonso424@hotmail.com

\section{Resumen}

Un análisis histórico muestra el surgimiento, desaparición, permanencia e influencia de escuelas de pensamiento económico que conceptúan de modo diverso el rol que debe desempeñar el Estado con respecto a la economía; a su vez, la relación Estado-Economía está mediada por la perspectiva antropológica que se tenga. Colombia ha sido receptaria, y en pocos casos creadora, de varias de las propuestas metodológicas de estas escuelas que han influido en la legislación y en la conformación de la economía de nuestro país.

\section{Palabras clave}

Rol del Estado, escuelas de pensamiento económico, caso colombiano.

\begin{abstract}
A historical analysis shows the appearance, disappearance, permanency and influence of the schools of economic theories that conceptualize in diverse ways the role that the State must perform with respect to the economy; at the same time, the State-Economy relationship is measured by the anthropologic perspective present at the moment. Colombia has been a receptionist and in few cases creator, of various methodological proposals of these schools that had influenced the legislation and the creation of the economy in our country.
\end{abstract}

\section{Key Words}

State role, schools of economic theory, economy, colombian economy 

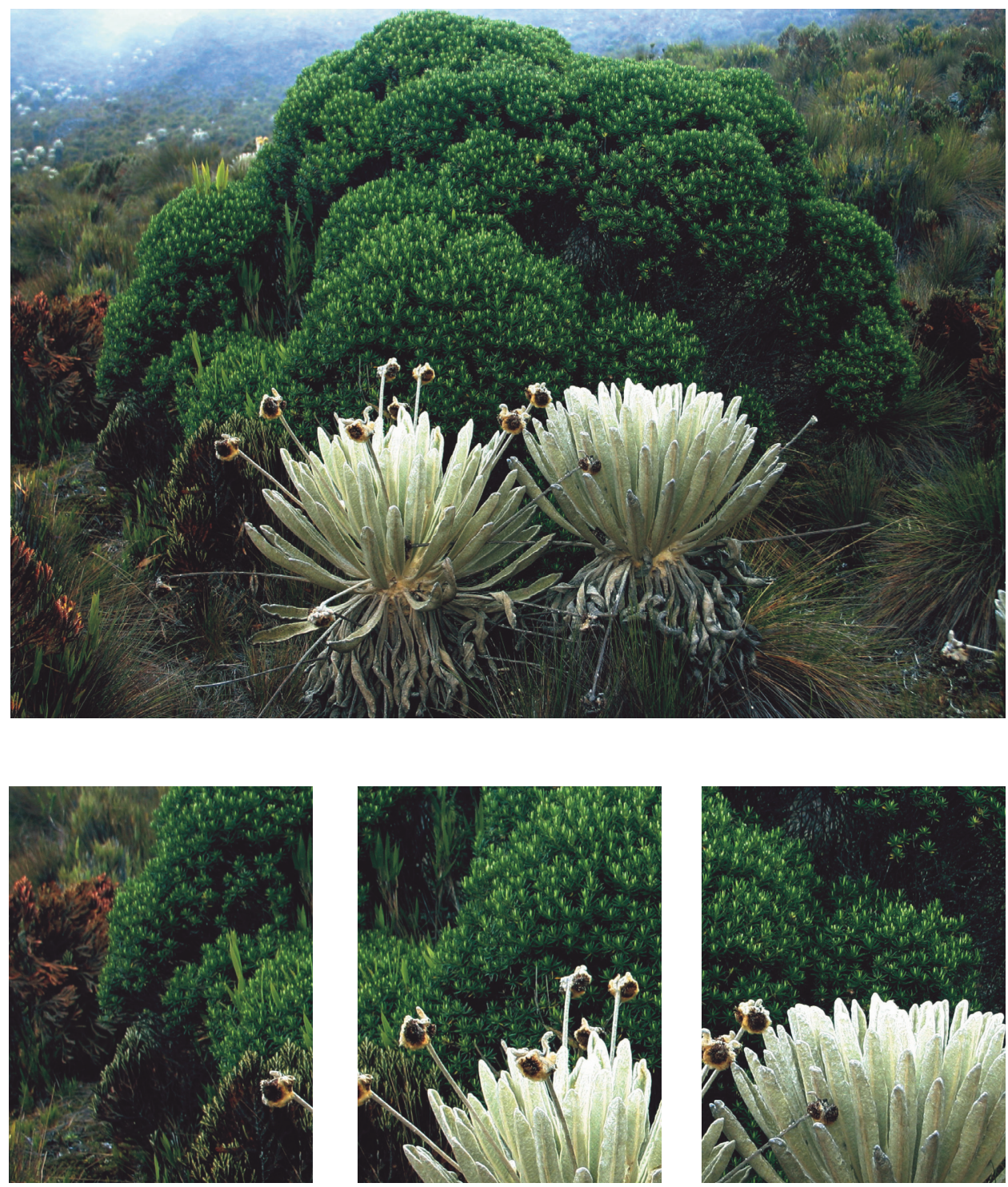

Frailejones y Romeros 


\section{LA INTERVENCIÓN ESTATAL EN LA ECONOMÍA: ELEMENTOS DE ANÁLISIS PARA EL CASO COLOMBIANO*}

Fray Luis Antonio Alfonso Vargas, O.P.

La historia muestra una dialéctica en la que el tránsito de la liberación económica a la intervención estatal está mediada por etapas de crisis. En el presente apartado se confluirá la perspectiva económica alrededor del tema en mención a partir de las escuelas de pensamiento económico más representativas y su influencia en los cursos de acción públicos en Colombia.

\section{De Aristóteles a Locke}

La configuración del orden social desde los pensadores clásicos se atribuye en mayor o en menor medida a la existencia de la intervención del Estado en el uso del poder. Desde Aristóteles hasta Locke se converge en la necesidad de un ente mayor, aunque con funciones diferentes en uno y otro caso, que permita la convivencia y el bienestar de la sociedad. Mientras el primero valida la formación del Estado como un acto natural inherente a la condición humana para el alcance del bien común, el segundo atribuye su existencia a la necesidad de protección de la propiedad privada y del establecimiento de reglas, así como penas y castigos para establecer el orden y la convivencia.

Según Bobbio (1993), antes de Locke existió un organicismo porque cada individuo era concebido como un elemento de un orden que lo superaba, la familia, la polis, el imperio, la iglesia. Desde el punto de vista económico correspondía al Estado como ejecutor del bien común dirigir la economía, dirigir la producción y distribución de bienes. En una visión ética de este proceso no es moralmente bueno la acumulación de bienes (y menos de capitales) porque esto contribuye a generar riqueza y miseria. El ideal antiguo y medieval, desde la aparición del cristianismo es una sociedad que, mediante los bienes, puede satisfacer las necesidades.

Es con Locke que aparece, desde el punto de vista político y moral la noción de individuo de tal forma que la autocomprensión del sujeto se hace con referencia a sí mismo y no a un ente superior. Bobbio (1993) caracteriza el Estado moderno que surge con Locke como un ente político que busca la seguridad en los goces privados, que limita el poder de los gobernantes, que garantiza los derechos naturales de las personas e interviene únicamente para evitar que un ciudadano cause daños a otros.

El texto revisa las escuelas de pensamiento económico sobre el modo diverso del rol que debe desempeñar el Estado con respecto a la economía. Se desarrolla en el marco de la Maestría en Derecho Público adelantada por el autor, Universidad Santo Tomás, Bogotá. 
Por lo tanto, para Locke el Estado debe intervenir lo menor posible en el curso de la economía y el mercado, no obstante debe garantizar el derecho de propiedad, el cual es connatural a la persona, lo que permite que cada individuo, a partir del derecho de propiedad pueda realizar los otros derechos naturales. La sociedad de Locke es un conjunto, necesariamente, de propietarios.

\section{Mercantilistas y fisiócratas}

El debate de la conveniencia del Estado en los sistemas económicos propiamente dichos, se inicia con el desarrollo de corrientes antagónicas tales como el mercantilismo y la fisiocracia. Los mercantilistas, a mediados de siglo XVI, reclamaron la necesidad de la presencia del Estado para expandir el comercio mundial, acumular riqueza y consolidar economías de la época, on el uso de instrumentos como las restricciones a las mercancías extranjeras y los incentivos arancelarios para las propias.

Dos siglos más tarde en Francia, los fisiócratas, seguidores de François Quesnay, defendían
"la eliminación de toda traba que impidiese el funcionamiento del orden natural establecido por Dios para bienestar de los hombres. A partir de allí, propugnarán la no intervención del Estado en la resolución de los problemas económicos" (Marsili, 2007)

y se constituía en la solución a la decadencia económica y especialmente agrícola que vivían los países en aquel tiempo. Entre sus postulados consideran que

“(...) El Estado debe mantener tal orden natural mediante tres reglas: el derecho a la propiedad, la libertad económica, y la seguridad en el disfrute de esos derechos y libertades" (Martínez, 2003).

La libertad económica según esta tradición será enmarcada por la frase laissez faire, laissez passer ${ }^{l}$, la cual transcenderá por toda la historia del pensamiento económico.

\section{Escuela Clásica}

La disciplina económica encontraría en la modernidad (siglos XVIII y XIX) su desarrollo, en la denominada escuela clásica atribuida a Adam Smith, con su obra Naturaleza y Causa de la Riqueza de las Naciones (1776); David Ricardo, Principios de Economía Política y Tributación (1817); y, John Stuart Mill con Sobre la Libertad (1859); quienes adoptarían mayoritariamente los postulados utilitaristas ${ }^{2}$ y fisiócratas, y establecerían también el orden natural como principio de racionalidad, el cual implica, en la práctica, un margen mínimo del Estado como ordenador de la

1. Aludía a la no imposición del Estado sobre temas económicos, no restricciones al comercio ni a las empresas.

2 Jeremy Bentham y David Hume, entre otros. 
actividad económica y relevancia de las decisiones individuales para el bienestar general.

Adam Smith hace un estudio del sujeto humano, desde el punto de vista moral ${ }^{3} \mathrm{y}$ luego le da implicaciones económicas. El sustento de su teoría es la noción de mano invisible. Cada hombre al actuar libremente y perseguir sus intereses individuales ó egoístas ${ }^{4}$ logra el bien social, debido a que una mano invisible regula el conjunto de los actuares individuales y los convierte en un bienestar general. Esta teoría era influida por la corriente filosófica denominada mecanicismo. Para Newton el universo funciona como una sumatoria de movimientos individuales guiados por una ley general universal. De igual manera, los estudios de biología mostraban que una abeja, por ejemplo, contribuía al bienestar y funcionamiento de todo el panal aunque ignorara el funcionamiento general de dicho panal.

A partir de esto, con Smith se crea la teoría de la división del trabajo y del valor, como fundamento del crecimiento económico de las sociedades, puesto que el hombre encuentra en la especialización la manera más oportuna de realizar el intercambio y obtener ganancia. En esta perspectiva, el valor real de las mercancías está dado por el costo que se invierte en su producción (capita 1 y trabajo). Sin embargo, Smith reconoce que hay cierto tipo de bienes especiales cuyo valor no lo determina el trabajo sino la escasez, por ejemplo, los diamantes ${ }^{5}$. Por lo cual define el doble carácter de las mercancías al poseer un valor de uso, dado por la satisfacción o utilidad que proporciona el bien a quien lo consume y un valor de cambio que es la capacidad adquisitiva de dicho bien para adquirir otros bienes, esta capacidad se definiría por el precio de mercado del bien determinado por el juego entre la oferta y la demanda.

Posteriormente a David Ricardo se le atribuye la creación de la teoría de las ventajas comparativas De acuerdo a los postulados de Smith aplicados al intercambio internacional, argumenta que el crecimiento económico encontraría su elevación en la medida que cada país se especializara en la producción de aquellos productos cuyas condiciones naturales le permitía promover con mayor facilidad, unos países debían producir lanas, otros cereales y así, los demás para fomentar el intercambio vía especialización, sin la obstrucción del Estado en el mismo. En el mismo sentido, John Stuart Mill expone el principio absoluto que debería gobernar las relaciones entre la sociedad y sus miembros, a saber, el principio de la no intervención de la autoridad, ya que las personas son soberanas en sus acciones.

3 Su obra Teoría de los sentimientos morales en 1759, es representante de tal tratado moral que en contraste con la figura central del egoísmo en la obra la Riqueza de las Naciones expone el papel de la simpatía como "criterio de aprobación o reprobación de la conducta" (De la Fuente y Gil, 1995).

4 De ahí la aplicación de su famoso ejemplo en el libro la Riqueza de las Naciones: "No es la benevolencia del carnicero, del cervecero o del panadero la que nos procura el alimento, sino la consideración de su propio interés. No invocamos sus sentimientos humanitarios, sino su egoísmo; ni les hablamos de nuestras necesidades, sino de sus ventajas".

5 Más adelante esta afirmación clasificaría los bienes de consumo como: inferiores, superiores y normales. 
Otra obra económica clásica fue El Capital de Karl Marx (1867), que al contrario de los liberales anteriormente expuestos, criticaba la postura de los liberales clásicos al ignorar el papel económico del Estado, puesto que concebía el intervencionismo como un eje necesario para mantener el sistema económico y social, tal como el capitalismo. Este último dadas las contradicciones entre las clases sociales terminaría acabado por la sublevación de la clase trabajadora.

\subsection{Los clásicos en Colombia}

Es de destacar la gran influencia que ejercieron los pensadores clásicos liberales en Colombia en lo corrido del siglo XIX en el diseño de la política económica, esta tuvo como base el libre comercio, expresado en los bajos aranceles y el intercambio de mercancías especialmente con Europa, bienes agrícolas por manufacturas. Florentino González, Salvador Camacho y Miguel Samper fueron los destacados pensadores económicos que influyeron en la época política del radicalismo liberal. La siguiente frase de Florentino González reivindica el sentimiento económico de la época:

"Libertad para producir y cambiar, he aquí lo que el legislador debe conceder a todos, y dejar a la inteligencia y a la actividad el campo libre para obtener las ventajas, que la poca habilidad o la pereza pretenden conseguir con una protección onerosa para la sociedad entera"6.

\section{Escuela Neoclásica}

Sin embargo, la tendencia liberal de los clásicos sería retomada y formalizada en términos matemáticos en el siglo XIX bajo el llamado neoclasicismo, de autores como Carl Menger, León Walras y William Stanley Jevons, quienes le brindaron universalidad y fundamentación al modelo económico liberal bajo conceptos como equilibrio general, competencia, utilidad marginal, costos marginales, costo de oportunidad ${ }^{7}$, entre otros, la base de la denominada microeconomía.

6 Abstracto tomado de la página editorial de la Revista de Economía de la Universidad del Rosario, Número 4, 2001. Resaltando lo contenido en Informe del Secretario de Hacienda al Congreso Constitucional de 1848 .

7 En el costo de oportunidad se estudia si la producción de $\mathrm{X}$ bien genera ganancias o pérdidas. El costo marginal significa que a mayor producción en el tiempo, menor costo de producción. El valor de la producción del segundo producto es menor que la del primero por lo que los costos de producción al pasar el tiempo son decrecientes. El ingreso marginal está determinado por el costo marginal decreciente: a menor costo marginal mayor ingreso marginal El equilibrio general está dado por el punto de encuentro entre el costo marginal y el ingreso marginal. Es el momento ideal de la economía. Las ganancias se producen en el encuentro de la oferta y la demanda. El equilibrio general se da por la suma de los equilibrios de las empresas. En este sentido no pueden existir monopolios porque rompen dicho equilibrio. 
Son las conductas de los productores y los consumidores que tratan do de maximizar sus beneficios y su utilidad las que conducen a una situación de equilibrio general, dada la plena competencia y libertad económica. El precio de todas las cosas es un resultado de la interacción entre su oferta y su demanda.

La teoría neoclásica parte del supuesto que el hombre como maximizador de beneficios; siempre busca lo que le genere mayor placer desde el punto de vista moral y mayor ganancia desde el punto de vista económico. Para que ello ocurra así deben existir dos principios básicos: el de racionalidad y el de información plena. Por el principio de racionalidad se entiende que el hombre ordena siempre sus preferencias, las valora y escoge la mejor para su beneficio. En un mercado libre escogerá racionalmente la mejor opción con el menor valor; es decir el bien de mayor calidad que cueste menos dinero ${ }^{8}$. Esto supone el segundo principio que es el de información. Los neoclásicos parten del supuesto que la información existe en el mercado y las personas en sus actuaciones económicas la utilizan de manera permanente y provechosa para elegir la mejor opción.

La aplicación de los dos principios anteriores, se convierte en la antesala del concepto de óptimo de Pareto que de manera simplificada, significa que cada individuo al actuar por medio de los principios de racionalidad y de información puede alcanzar una situación según la cual genera bien económico propio sin dañar el de los otros. Este concepto trascendería la esfera económica, y sería el sustento para evaluar todo tipo de intervenciones sociales en términos de eficiencia y equidad.

Los historiadores de la economía afirman que la paz decimonónica se dio gracias a la realización del modelo neoclásico. Porque permitió una economía con pocos monopolios y multiplicidad de empresas, controladas por el modelo oferta- demanda a escala global, aunque entrara en contradicción y colapsara más adelante.

La Escuela Austriaca, de corte neoclásica, se ha mantenido durante todo el siglo $\mathrm{XX}$ en su tradición metodológica, fuertemente crítica con todos los paradigmas dominantes. Entre los más recientes y destacados autores se encuentra el Nobel de Economía de 1974 Friedrich Agust von Hayek.

\section{Keynesianismo}

Pero la teoría que le concedió a la economía el status de ciencia, entraría en contradicción en la crisis económica de 1929. La respuesta para solventar la crisis estuvo a cargo del economista John Maynar Keynes en 1936 con la publicación de su Teoría General de la Ocupación, el Interés y el Dinero, quien manifiestó la contradicción de los postulados liberales del equilibrio vía libre mercado $y$

8 Hay que destacar que hoy no sólo se aplica la teoría microeconómica a bienes del mercado en el cual se compra y se vende, sino también en situaciones o bienes de no-mercado bajo la esfera del comportamiento individual, tales bienes son las normas, sanciones, los bienes ambientales, entre otros. 
recomendó, a diferencia de sus predecesores, la presencia activa del Estado como estabilizador de la economía.

Se considera a Keynes el creador de la macroeconomía por cuanto hace un análisis de las variables económicas en contextos agregados (grandes conglomerados de productores y consumidores, niveles de empleo, precios y dinero en circulación, entre otros..). En este sentido, Keynes trabaja sobre el supuesto que la producción nacional (manejado en términos prácticos como Producto Interno Bruto) es igual a la sumatoria entre el consumo más la inversión más el gasto público más la diferencia entre exportaciones e importaciones.

$$
\mathrm{PIB}=\mathrm{C}+\mathrm{I}+(\mathrm{GP})+/-(\mathrm{E}-\mathrm{I})
$$

Según Keynes en tiempos de crisis económica el Estado debe incentivar la variable Gasto Público (GP) para reestablecer el equilibrio económico, así como la inversión de los particulares. El Estado realiza el gasto público por medio de la creación de infraestructura, inyección directa de dinero y provisión de bienes y servicios. Para esto los intereses bancarios a los particulares deben ser bajos para promover el acceso permanente al mercado financiero y con ello tener recursos para aumentar la producción nacional. El Estado capta ingresos por los impuestos que son acordes con los bienes que posea cada ciudadano, a mayor renta, mayores impuestos.

Así fundamenta Keynes que las leyes económicas van más allá de la relación oferta y demanda, puesto que las personas no consumen todos sus ingresos (existe el ahorro) y las decisiones de inversión se basan en las expectativas (sean de particulares o empresas), es decir, existe incertidumbre la cual distorsiona el axioma de que toda oferta crea su propia demanda y el mercado por su libre movimiento se vacía (oposición a la Ley de Say).

En la práctica esta escuela

"significó la generalización del Estado de Bienestar entendido como el conjunto de acciones públicas tendientes a garantizar a todo ciudadano de una nación el acceso a un mínimo de servicios que mejore sus condiciones de vida" (Oszlak, Citado por Marsili, 2007, 50).

Estas acciones incluirían un papel activo como regulador de la economía que permitirá impedir las crisis y fomentar el crecimiento.

La crisis económica unida con los devastadores efectos de la segunda guerra mundial sobre la humanidad y las instituciones imperantes, se constituyeron en el escenario propicio para implantar una nueva estructura económica de base keynesiana, respaldada por los Estados, para estabilizar la sociedad. Tal estructura se inició con la formación de organismos supranacionales ${ }^{9}$ que respaldaran financieramente a las naciones en crisis, en un plan de restauración económica, basadas en la idea intervencionista del Estado, las cuales con el fin de aumentar

$9 \quad$ Entre las organizaciones creadas para tal fin se encuentran el Fondo Monetario Internacional y el Banco Mundial. 
la demanda agregada, incentivaría el consumo vía gasto público; así el Estado se convertiría en el ente subsidiador de todos sus ámbitos de actuación, los cuales se extendieron en la posguerra debido a la nueva orientación de lo social, enmarcada por los derechos humanos, y a la necesidad de consolidación económica-industrial de las economías en el mundo.

\subsection{La teoría de Keynes en América Latina}

En el periodo de la posguerra, para América Latina se recomendó fortalecer la industria interna como sustento para el crecimiento económico, que para la época era casi inexistente, este proceso se conoció como el Modelo de Sustitución de Importaciones de la Comisión Económica para América Latina (CEPAL), dirigido por Raúl Prebish. De acuerdo a Garay (s.f.), desde 1945 se adoptó el modelo con un propósito industrialista en el eslabón manufacturero:

“(...) la creación de Instituto de Fomento Industrial (IFI), en 1940 sería un elemento fundamental para el apoyo de la inversión y montaje de sectores industriales como la industria química, del caucho y metalúrgica, entre otras".

Las ideas expuestas por la Cepal argumentaban el estancamiento económico de los países de la "periferia" radicaba en

“(...) el modelo clásico basado en la división del trabajo, en el cual los países del centro se especializaban en bienes intensivos en capital y los de la periferia en bienes intensivos en mano de obra" Garay (s.f.).

La política de Keynes en América Latina buscó desincentivar la variable Comercio Internacional imponiendo altos impuestos a las importaciones de mercancías para promover la producción de las propias. De igual manera, los Estados comenzaron a intervenir al proveer de manera directa los servicios de salud, educación y el mismo Estado se convirtió en el mayor empleador ${ }^{10}$.

Además, el Estado colombiano asumió nuevas responsabilidades de acuerdo a la nueva ola de derechos humanos, de los cuales se convertía en su directo proveedor (salud, educación y demás en el país fue un proceso de creación de aparatos gubernamentales para la prestación de tales servicios, ejemplo de ello fue la creación en la década de los sesenta de un sistema de salud acompañado de grandes inversiones en infraestructura hospitalaria.

Sin embargo, la prolongada crisis de los años setenta

“alteró la perspectiva de la intervención pública. La llamada crisis del petróleo introdujo la concienciación de que la sobre-dimensión del

10 En Colombia por citar algunos ejemplos en 1940 se creó el Ministerio de Salud; los hospitales San Juan de Dios se crearon durante el gobierno de Rojas Pinilla; en la década del 60 se crearon los hospitales universitarios en lo que se comenzó a brindar un sistema de prestación de servicios de salud. De igual manera el Estado Colombiano incrementó su aparato burocrático. 
Estado había contribuido al desequilibrio financiero mundial. Una nueva corriente ideológica marcaría así la década de los 80" (Marsilli, 2007).

\section{Escuela Monetarista}

Al tiempo que avanzaba el modelo de Keynes y se aplicaba a más economías en el mundo, autores como Milton Friedman y F, V. Hayek, mantuvieron su constante critica a tal modelo argumentaban los efectos nefastos que traería consigo la planificación centralizada del Estado. La crisis del modelo en los años setenta abrió de nuevo el camino para los autores señalados, puesto que los postulados keynesianos cayeron en contradicción al presentarse en las economías hiperinflaciones y desempleo masivo.

Este hecho unido al fracaso de otros sistemas como el socialismo, otorga a esta escuela viabilidad para implementar sus postulados en las políticas económicas que iniciarían las llamadas reformas estructurales, expresadas en primera instancia en el denominado Consenso de Washington, documento escrito por John Williamson en 1989, que sintetiza las recomendaciones de política recomendada desde los monetaristas para el ajuste de las economías emergentes, conocido hoy como el fundamento del neoliberalismo.

Tales medidas de ajuste estatal se resumen en el siguiente listado: (i) Disciplina fiscal, (ii) Reordenar las prioridades del gasto público, (iii) Reforma de impuestos, (iv) Liberalización de las tasas de interés, (v) Una tasa de cambio competitiva, (vi) Liberalización. (vii) Liberalization of Inward Foreign Direct Investment, (viii) Privatización, (ix) Desregulación, (x) Derechos de propiedad.

\subsection{La escuela monetarista en Colombia}

En Colombia tal proceso de ajuste inicia con la administración del presidente Virgilio Barco, al incentivar el proceso de apertura económica al

"reducir progresivamente las restricciones cuantitativas a las importaciones. Se buscaba incrementar gradualmente el nivel de exposición de la economía colombiana a la competencia externa para, de esta forma, buscar alcanzar mayores niveles de competitividad y de desarrollo" (Garay, s.f).

El gobierno de César Gaviria consolidaría el proceso de apertura de mercados e iniciaría varias reformas tendientes a cumplir con las políticas del Consenso de Washington. Pero la apertura vendría acompañada de una política fiscal restrictiva (disminución de impuestos y recaudos, para incentivar el ahorro público y el manejo eficiente del gasto).

La liberalización del comercio de acuerdo al proceso de apertura económica bajo el gobierno de Gaviria abrió las puertas del mercado colombiano de acuerdo a instrumentos tales como la reducción y eliminación de aranceles, lo cual buscaba 
incentivar el consumo, la variedad del mismo, la mejora industrial de las empresas y el fortalecimiento del comercio.

Asimismo se ideó una nueva estrategia para hacer frente a las crecientes demandas sociales de servicios tales como la salud y la educación, esta consistía en provisión privada de tales servicios bajo la guía del Estado.

\section{El neoinstitucionalismo}

Otras corrientes surgieron a través del siglo XX y solo encontraron atención a finales de siglo y fueron $¥$ las que retomaron el análisis económico tradicional desde otras disciplinas como el derecho y la ciencia política. Una de estas corrientes de pensamiento fue la llamada escuela institucionalista de principios de siglo XX, la cual tuvo como centro de análisis la influencia de los hábitos de conducta y de pensamiento de la comunidad plasmados en instituciones sociales sobre el sistema económico. Uno de los más destacados autores de dicha corriente fue Thorstein Veblen quien retomó explicaciones desde la biología (darwinismo) para explicar el comportamiento económico y social.

Asimismo, la naciente interdisciplinariedad de la economía tardaría en darle importancia a la obra de otro teórico Ronald Coase en 1937 con la publicación de la Naturaleza de la Firma, en donde explica que la carencia del modelo económico neoclásico radica en la ausencia de elementos como los costos de transacción y los derechos de propiedad. Después de mitad de siglo sus ideas cobrarían relevancia con la divulgación del artículo El problema del costo social, el cual despejaría el camino para nuevas líneas de investigación como el Análisis Económico del Derecho, Organización Industrial, la Elección Pública, los contratos, regulación económica y la economía de la información, todas ellas agrupadas (aunque no de manera articulada) en una corriente denominada neoinstitucionalismo.

El neoinstitucionalismo tomó como núcleo de referencia el modelo neoclásico atribuyéndole ciertas modificaciones, intentó llenar los vacíos que, desde distintas corrientes, habían sido señalados y trazó puentes para el estudio integral. Douglass North premio Nóbel de economía en 1993 estudió a Ronald Coase y Thorstein Veblen, entre otros, y fórmuló una teoría de las instituciones cuyos postulados principales se pueden sintetizar así:

1. North entiende la institución en un concepto amplio, como las "reglas del juego en una sociedad o las limitaciones creadas por el hombre que dan forma a la interacción humana" (1993; 13). Éstas pueden ser formales (reglas, leyes, constituciones) o informales (normas de comportamiento, convenciones, cultura y códigos de conducta, entre otros.) que en "conjunto definen la estructura de incentivos de las sociedades y específicamente de las economías" (1993).

2. North critica la teoría neoclásica en sus principios de racionalidad y de información. El hombre no es enteramente racional, sino que su racionalidad 
está limitada por las instituciones. Tampoco posee información completa porque siempre en el mercado la información es fragmentada.

3. Tampoco se da el óptimo de Pareto puesto que en la economía existen competencias imperfectas; la utilidad y crecimiento de unas empresas generan en muchas ocasiones la destrucción de otras como en el caso de los oligopolios.

4. Cada nación evoluciona de una manera diferente de acuerdo con las instituciones propias. Esto ocurre en el campo moral, económico y político. (North, 1995, 139-151).

5. El Estado debe regular comportamientos, conductas, derechos de propiedad de una manera eficiente para crear marcos institucionales en donde se pueda desarrollar la economía como medio de desarrollo de cada país.

6. El estudio institucional de la economía es el único método válido para poder mejorar el índice de desarrollo económico, sólo a través de la modificación de las instituciones desde el punto de vista ético, político y económico se puede conseguir un mejor desarrollo económico que trae beneficios sociales.

\subsection{El neoinstitucionalismo en Colombia}

Las nuevas tendencias económicas y una nueva organización mundial (económica y geopolítica) exigían al Estado cambiar su estrategia regulatoria para lograr la coordinación, eficacia, eficiencia y equidad en sus funciones que respondieran a tales exigencias.

En Colombia una Nueva Carta de Derechos en 1991 exigía nuevas responsabilidades al Estado para brindar derechos y oportunidades de acceso a bienes de primera necesidad. Las políticas neoliberales iniciadas en los noventa, más un instrumental teórico-analítico renovado fue el marco para introducir diversas reformas, ejemplo de ello la nueva caracterización del Estado como garante de la prestación de servicios públicos. Tal oleada de reformas tocó sectores como la salud (por medio de la Ley 100 de 1993), el empleo (flexibilización del mercado laboral, nuevas figuras de contratación), la construcción de vías (concesiones viales a privados), el sector eléctrico (separación de la regulación, la producción y la distribución: Ley 142 de Servicios Públicos y la Ley 143 Eléctrica) y sector gas, entre otros.

La descentralización administrativa fue otro de los grandes cambios en la estructura orgánica del Estado colombiano, los antecedentes inmediatos del proceso de descentralización remontan a la administración de Belisario Betancur, la cual elaboró un proyecto global de descentralización política, administrativa y financiera discutido y aprobado por el Congreso en 1983 en cuanto a la parte financiera y en 1986 en cuanto a la parte política y administrativa. En 1986 llegó un nuevo Gobierno con la elección de Virgilio Barco, el cual según el análisis de Blanquer y Fajardo (1991), presentó 
(...) una política menos voluntarista en materia de Reforma del Estado y tomó algunas medidas, por Decreto o por Leyes, de aplicación y de ampliación de la descentralización (...). La expedición del Decreto 77 de 1987 es la consecuencia lógica de las leyes del 83 y 86, en el cual aparece la descentralización como una necesidad impuesta por el contexto nacional e internacional.

Tal proceso se consolidaría con la puesta en marcha de la Ley 60 de 1993 y su reforma en el 2001 por medio de la Ley 715. Estas reformas buscaron la eficiencia del aparato Estatal que permitían al sector privado actuar bajo ciertos límites impuestos por el ente mayor para simular la formación de mercados que redunden en mejores precios y cobertura total. En este sentido, Ayala y Millán, 2002, afirman:

La sostenibilidad financiera sería conseguida mediante la atracción de inversionistas privados y el pago de los costos reales del servicio por los consumidores, mientras que la sostenibilidad social se lograría mediante el establecimiento de subsidios claros y transparentes, concentrados en la población objetivo y procurando minimizar las distorsiones a las señales tarifarias.

\section{Nuevas perspectivas económicas: más allá del debate entre el Estado y el Mercado}

Más allá del debate sobre el Estado o el mercado como estabilizador de la social, Amartya Sen en su libro Desarrollo y Libertad (1999), plantea un punto medio en el cual es posible obtener ventajas económicas en términos de desarrollo, justicia y equidad valiéndose de mecanismos estatales de subsidiariedad y libre funcionamiento del mercado. En este sentido el nivel de bienestar social depende del conjunto disponible de capacidades para funcionar. Si bien los recursos (habilitaciones) son indispensables para tener capacidad, son aquellas las que definen el uso y el disfrute de libertades de los individuos.

En este sentido, para Sen la intervención debe existir exclusivamente para garantizar el acceso y disfrute de libertades (derechos) de las personas, se puede decir entonces, que el papel del Estado es el de garante de la equidad en la sociedad y desde su perspectiva "el paternalismo puede definirse como la restricción de la libertad en beneficio de aquel cuya libertad se limita" (Cejudo, 2007). En otros términos, los menos aventajados constituyen el foco estatal para brindar capacidades que redunden en el aprovechamiento y disfrute de libertades individuales.

Durante su trabajo en el Banco Mundial, Sen ha creado fórmulas para medir si los Estados proveen las habilitaciones y capacidades básicas para que se logre satisfacer las necesidades fundamentales y se disfruten las libertades de los ciudadanos. 


\subsection{Políticas y recomendaciones del Banco Mundial sobre la intervención estatal en la economía colombiana}

Guigale (2003) sintetiza el informe de recomendaciones del Banco Mundial sobre lo que debiera contener la agenda del nuevo periodo presidencial colombiano en el tema económico. El informe resalta dos situaciones que impiden el desarrollo del país: la violencia, y la crisis económica, surgida a partir de 1998. Por lo cual, según el Banco Mundial la tarea principal del nuevo gobierno ha de ser fomentar un desarrollo económico como condición necesaria para la paz. Por medio de 1) Conseguir un crecimiento rápido y sostenible. 2) Compartir los frutos del desarrollo con todos los colombianos. Y, 3) Construir un gobierno de calidad.

La primera prioridad es lograr un desarrollo económico rápido y sostenible. ${ }^{11}$ Para el BM son 5 las intervenciones que debe hacer el gobierno:

1. Un régimen macroeconómico más propicio que consiste en corregir el desequilibrio financiero del sector público y la acumulación de la deuda ${ }^{12}$. Para ello propone reducir el gasto y aumentar los recaudos.

2. La reforma al sector financiero, que consiste en la reestructuración de la banca y reforma del sistema de pensiones en términos fiscales.

3. En la prestación de los servicios debe existir una mayor participación privada y debe tener una mayor cobertura hacia los pobres.

4. El renacimiento de la economía rural, que posibilite el mercado real en vez de oponerse a él con subsidios que trastornan el mercado de la tierra y de los productos.

5. Políticas de crecimiento y protección ambiental. Desarrollar el mercado de las emisiones de carbono.

En segundo lugar, establece que lo importante para poder ser partícipe de los frutos del desarrollo económico es proporcionar a todos los ciudadanos las "herramientas" para poder participar de ese crecimiento. Por ello hay que crear "unos mejores mecanismos para la formación del capital humano y mejores mercados para vender ese capital"13. Según el BM, la intervención que debe hacer el gobierno a este respecto la podemos sintetizar así:

1. Reformar la educación pública y el sistema de salud, estructurando procesos de rendición de cuentas. El BM critica estos dos sistemas por su alto costo para el gobierno frente a su poca calidad.

11 el BM “(...) en promedio, cada punto porcentual de incremento del PIB per cápita reduce la pobreza en $0,6 \%$ (en un cuarto de millón de personas)" Ibíd., p. 3.

12 Dice el informe que la clave será "gastar menos y gravar más pero sin ralentizar la economía". Ibíd. p. 4

13 Se observa en el lenguaje la visión economicista de la persona. Proporcionar "herramientas"; "capital humano"; "mercados para vender el capital humano". Pareciera que la persona se reduce a un eslabón más de la cadena económica. 
2. Es necesario crear, según el BM, un régimen legal y normativo del mercado laboral en donde los pobres puedan explotar su capital humano, de acuerdo con la economía moderna.

3. Un sistema de protección social adecuado que realmente proteja a los desplazados por el conflicto, integrándolos pronto al sistema económico.

Y por último el BM parte de la premisa de la poca credibilidad del mismo Estado, lo que imposibilita el margen de maniobra de cualquier gobierno. Por ello, la primera tarea es la reforma del Estado en sí mismo. Esta reforma no es, fundamentalmente burocrática, sino funcional. Dice el BM: se trata de

"mejorar la forma en que el Estado cumple con sus funciones principales:

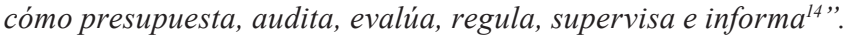

El contexto en el que se realizan dichas funciones debe reformarse en tres frentes:

1 Hacer más eficiente la descentralización para que los departamentos y municipios tengan disciplina fiscal y mejoren en la captación de recursos propios, pues el régimen de descentralización se puede volver insostenible.

2. Fortalecer los mecanismos para luchar contra la corrupción.

3. Modernizar el sistema judicial para que responda a los principios de calidad y eficiencia.

Este informe es compatible tanto con supuestos propios de la escuela monetarista, neoinstitucionalistas, aunque con un enfoque propio de los postulados de Sen.

Si bien la primera propuesta se ha cumplido de manera relativa desde la década pasada, son aún pocos los resultados en materia de crecimiento económico. La segunda propuesta del BM relacionada con "compartir los frutos del desarrollo entre todos los colombianos" no ha mostrado un buen desarrollo. Por el contrario, el margen entre los ingresos de los más ricos con respecto a de los más pobres ha aumentado en estos años. $\mathrm{Y}$ las medidas del gobierno no han tenido como direccionamiento conseguir que las clases pobres accedan a la propiedad. Por el contrario, se incentiva permanentemente el consumo y no el ahorro. Los intereses de ahorro no son atractivos por lo que los ciudadanos al final depositan sus recursos en captadoras de ahorro al margen de la legalidad.

La tercera propuesta relacionada con "construir un gobierno de calidad" es de vital importancia debido por los tres elementos que conlleva: en indispensable hacer más eficiente el manejo de la descentralización, crear medidas de intervención eficaces contra la corrupción y hacer que el sistema judicial tenga calidad y eficiencia. En este sentido un trabajo desde la perspectiva de North serviría para analizar la relación economía-sociedad, desde las instituciones formales como la legislación o informales como las costumbres, para proyectar estrategias que lleven a esas instituciones a ser más eficientes desde el punto de vista de la calidad humana. Esto implicaría un trabajo en educación, en valores, en cohesión social, que repercuten en otras instituciones como las económicas.

14 Ibíd., p. 5, y, p. 43 ss. 


\section{CONCLUSIONES}

La noción del papel que debe desempeñar la economía en los grupos humanos ha surgido de la misma concepción que se tiene de la persona humana. Cada pensamiento económico supone una visión antropológica, en la que el concepto de libertad es básico para determinar el modo como se debe organizar la economía. Y esta organización se da por medio de normas, es decir a través del derecho. Así pues, hay tres conceptos que la historia de las corrientes económicas muestran entrecruzados: la noción de libertad humana, de economía y de derecho.

De lo anterior podemos concluir que la economía busca organizar los recursos de acuerdo con la noción antropológica, sobretodo la noción de libertad; así la economía se entendería como una concretización de la antropología, que se normativiza por medio del derecho. La escuela económica que se aleja un poco de esta perspectiva es el neoclasicismo que pretendió hacer del derecho una ciencia eminentemente matemática; no obstante, como pensamiento general el neoclasicismo también es una escuela que buscó matematizar toda actividad humana y reducirla a formulaciones cuantitativas; las corrientes actuales de economía de corte humanista, como la de Amartya Sen, retoman formas tanto cuantitativas como cualitativas para estudiar los resultados de la economía en la sociedad.

Bobbio habla de dos grandes etapas de la historia humana: el organicismo y el individualismo. En la primera etapa el hombre es parte de un todo, por lo que la economía debe ser controlada por el gobernante, que representa el conjunto social. Con la aparición del individualismo la economía es una acción que deben controlar los particulares; esto da origen a la burguesía y con ella al capitalismo. La cuestión es si esa libertad que la modernidad concede al individuo debe ser absoluta o pueden existir intervenciones por parte del Estado con el propósito de regular la economía.

La historia muestra una dialéctica en estas regulaciones. Para unas escuelas el Estado debe tener un gran poder de intervención; para otras un poder limitado; para otras el Estado debe ser un simple espectador, limitar su actividad a garantizar la seguridad. De uno a otro modelo se ha pasado por diversos motivos: crisis económicas, imposiciones de organismos extranjeros; desarrollo de las mismas economías.

En cuanto a Colombia la influencia de pensamientos económicos, europeos y norteamericanos ha sido notorio. La historia muestra la influencia de la escuela keinesiana, del monetarismo, del neoinstitucionalismo, por mencionar sólo unas; de igual manera, algunos partidos políticos de izquierda, así como las insurgencias dicen seguir, desde el punto de vista económico, la escuela marxista.

El Banco Mundial dio unas recomendaciones en el 2003, que podríamos llamar unas directrices de políticas económicas. Un buen porcentaje de estas recomendaciones se han desarrollado por la intervención del Legislativo y del Ejecutivo. Los resultados dividen opiniones: unos los ponderan, otros los critican. Los que cuestionan estas políticas se basan en mediciones de índices de pobreza y miseria, desempleo y subempleo, calidad de educación y de salud, buscan demostrar 
que la intervención del Estado que aplica estas políticas del consenso de Washington, han favorecido a las entidades financieras, las grandes empresas, las prestadoras de salud, pero en muy poco a la calidad de vida de la población, que se suponía era el objeto principal de dichas intervenciones.

\section{REFERENCIAS}

Álvarez, J. F. (2001). Capacidades, libertades y desarrollo: Amartya Kumar Sen. En Máiz, R. (comp.). Teorías políticas contemporáneas, Tirant lo blanch, Valencia, pp. 381-396. Recuperado en http://www.uned.es/dpto_log/jalvarez/publicaciones/ sen2001. pdf

Aristoteles. (s.f.). La Política.

Ayala, U. \& Millán, J. (2002). La sostenibilidad de la reforma del sector eléctrico en Colombia. Recuperado de ftp://ftp.fedesarrollo.org.co/pub/destacados/ Resumen02181pdf fecha de recuperación

Blanquer, J.M \& Fajardo, D. (1991). La descentralización en Colombia: estudios y propuestas. Bogotá: Universidad Nacional de Colombia, Facultad de Ciencias humanas.

Bobbio, Norberto. Liberalismo y democracia. Bogotá: Fondo de Cultura Económica, 1993.

Cejudo, Rafael (2007). Capacidades y Libertad. Una aproximación a la teoría de Amartya Sen. Revista Internacional de Sociología. Vol. LXV, No. 47, mayo - agosto 2007. ISSN: 0034-9712. P., 11.

Clavijo, Sergio. Fallos y fallas de la Corte Constitucional. Bogotá: Alfaomega, 2001.

De la Fuente y Gil. (1995) ¿Hay contradicción entre la Teoría de los Sentimientos Morales y La Riqueza de las Naciones? Recuperado de http://www. riesgoycontrol. net/documentos/Smith_delaFuente.pdf

Florentino González (1805-1875) Revista de Economía. Universidad del Rosario (2001). Número 4. Recuperado de: http://www.urosario.edu.co/economia/ documentos/v4nlabstracts(2001).pdf

Garay, L. J. (s.f.). Composición y estructura económica colombiana. Biblioteca Luis Ángel Arango. Banco de la República. Recuperado de http://www.lablaa. org/ blaavirtual/economia/industrilatina/203.htm, el 17 de mayo de 2009.

Guigale, M. (2003). Colombia fundamentos económicos de la paz. Bogotá: Banco Mundial en coedición con Alfaomega Colombiana, S.A. 2003. Colección: libros de cambio.

Hayek, F.A. (1997). Los fundamentos de la libertad tomo I. Barcelona: Folio S.A.

Kalmanovitz, S (2001). Las instituciones colombianas en el siglo XX. Bogotá: Alfaomega.

Locke, J. (s.f.). Segundo tratado sobre el gobierno civil. 
Martínez, J. C. (2001). Breve historia del pensamiento económico. La Economía de Mercado, virtudes e inconvenientes. Recuperado de http://www.eumed.net/ cursecon/1c/pensamiento-economico.htm consultado el 7 de mayo de 2009.

. Conferencia de Douglass North, 9 de Diciembre de 1993. Mayo 15 de 2009 .

Marsili, M. (2007). Repensar el Estado. Ponencia presentada en el IV Congreso Argentino de Administración Pública. Sociedad, Gobierno y Administración Pública. Buenos Aires, 22 al 25 de agosto de 2007. Recuperado de www.ag.org.ar/4congreso/ Ponencias/Marina.doc el 15 de mayo de 2009.

North, D. (1993). Instituciones, cambio institucional y desempeño económico. México: Fondo de Cultura Económica. 